\title{
How to Improve the Athletes' Physical Fitness
}

\author{
Bin Xu \\ College of Foreign Languages, Northeast Dianli University, Jilin, 132012, China
}

\begin{abstract}
Sports training includes physical, skill, tactics, psychology and intelligence ability training. The physical training is an important part of sport training among them. Physical condition has direct influence on the athletes' performance level. We should carry on the analysis on the physical training of the athletes, and point out the role of physical training in the course of the game, at the same time, point out the existing problems of the development of physical training and some related measures and suggestions.
\end{abstract}

Keywords-physical fitness; physical training; sports training; excessive training

\section{INTRODUCTION}

In sports training, physical training plays a key and leading position. If a great athlete wants to achieve excellent results and climb up to the peak of world sports fitness, the first is to lay a good foundation on physical fitness. Physical fitness is a key factor which affects the improvement of the level of the movement, so we should grasp the athlete's physical training. The traditional athletics powers have attached great importance to the physical training, not only the development of systematic theory; practice experience is also very rich. In China, both in theory and in practice, there is not paying enough attention to physical training, which needs leading to many physical educators' reflection on the prospects for the development of sports.

\section{THE DEFINITION OF PHYSICAL FITNESS}

Physical fitness includes physical ability of actively adapting to life, the ability of working and excising, and the ability of keeping resistance to disease, adapting to the environment of the survival. Moreover, it also includes tissue and organ system function, the basic sport ability in sports activities. Classified from the training point of view, it includes the general physical training, special physical training and comprehensive physical fitness training. It is determined by the human congenital and acquired exercise body shape, physiological function, physical quality and other factors.

\section{EFFECTS OF PHYSICAL TRAINING IN THE DEVELOPMENT OF THE COMPETITION PROJECT}

\section{A. Physical development can effectively prevent the athletes' injury}

Good physical fitness is the basis for sports. An athlete who has good physical fitness not only can increase the efficiency of learning sports skills, but also can reduce the incidence of injuries and accidents caused by the movement. Physical training, especially physical quality training, has great effect on preventing track damage. Strength training is the key to preventing injury in track and field sports , the balance ability can not only reduce the injury, also can be in after injury, reduce the probability of re injured endurance quality improving for delaying fatigue to reduce sports injury plays a role can not be ignored is sensitive, coordinating quality improvement can be flexible training and enhance the body's stress ability and self the ability to improve the protection coordination of joint and muscle flexibility, improve the regulation against muscle of the central nervous system and the ability of tension and relaxation to reduce sports injury also has the important effect.

\section{B. Physical development is the foundation of the development of sport training so as to improve the competitive ability}

Sports training include physical, skill, tactics, psychology and intelligence ability training. Physical training is an important part of sports training. It is the process of combining several special needs, and improving the athletes' body shape, improving the organ system function of each athlete body, making the full development of sports quality, promoting and enhancing the sports performance through the reasonable load action. Through physical training, athlete can change the body structure of the external shape, shape the sound, specialneeded body, almost all the body shape training of the track events is basically realized through special training methods and means.

\section{Physical development urges the athlete to maintain good mental state}

The rapid development of modern competitive sports, the requirements for athletes' ability are very high in various aspects. In training and competition, athletes not only consume huge physical energy, but also pay a huge psychological energy. While the effect physical state plays on the mental state can not be ignored. Adequate physical reserves can save enough physical energy for the game, provide a guarantee for the stable mental status before competition, and be conducive to play the best competitive state in the race.

\section{Physical development can improve the exercise intensity and load}

Track training is not a simple repetition year after year, simple repetition can only make the body ability stay at the original level, if you want to have greater load and 
intensity training on the basis of the original, the only thing to do is to continue to strengthen the physical training so as to adapt to the gradual increase in the training load and intensity and improve the competitive level.

\section{PROBLEMS OF PHYSICAL TRAINING EXISTING IN COMPETITIVE SPORTS TRAINING}

\section{A. Guiding ideology of physical training is not clear enough}

In the track events, physical fitness is one of the most important factors that could influence the goal. The essence of practice and competition is the physical contest. Race and hurdle technology need more physical fitness, besides, other projects have to fight through physical strength.

Previously, because of the economic and historical reasons, China's understanding about physical fitness is very backward, even in the state of nature, there are not development of consciousness, competition is only rely on the most primitive means of exercises. With the development of society, our nation begins to develop the physical training with specific purpose. In order to improve the sports level, boss He proposed sports circles to "training guiding ideology and principle of competition", but "the scientific level is not high, with" low training efficiency.

\section{B. Part of the project is highly recognized, but scientific} level is not high enough

Since the "puts forward the training principles competition", part of coaches in China has started to have a discussion about the scientific physical training, but the outcome of the discussion and understanding is not mature, comprehensive. In early twentieth Century 80, our nation starts to raise the scientific level of general training. In 90, more and more attention is paid to the scientific sports training. Led by Russia and Germany' training theory and principles, China also began to look at the physical training from the angle of science.

In 1996, Coach Sun Haiping once in "track and field" magazine presents "achieve maximum benefits with the least input training" point of view, but in theory and the training field and no response, today, fortunately, sun coach "ten years grinding sword", will own training concept into practice and achieved success finally. This shows that China is still in the initial stage of physical fitness training on understanding on the whole, for the most active and useful in training information is still difficult to grasp.

\section{Lack of understanding about special physical training}

There is no lack of domestic high-level athlete in part of the track and field project, but the movement achievement remains stagnant after reaches a certain level,, and is difficult to access to the advanced world level, and finally have to end career. The main reason is the "speed barrier" plateau phenomenon "'. For the purposes of physical events, in fact, all of them can use "physical obstacles" to explain. The lack of deep understanding and awareness about the special physical ability training, the training level in the high level stage failed to get further improvement, this is the he main reason that China's athletes fail to show themselves in the international sports world. To lay the foundation at a young age is the target for physical training, it should be based on the general physical. While to get outstanding achievements in the stage of a high level, it should be based on the special physical training mainly. A deep understanding of this point or not, is the key factor to decide the success or failure of the training, many sports teams to the high level athlete is still a lot of implementation of the low phase of the general physical training, but has not realized the special physical fitness is a direct factor to affect athletic performance quality.

\section{The discordant in the combination between the physical training and technical training}

Track project needs physical fitness, physical training is at the core of the whole sports training. Therefore, in the training, we should lay emphasis on the physical training, especially in the physical quality training, this is a relatively common phenomenon, it is of special physical exercise over emphasized, thus ignoring the other physical elements of the training, some athletes also ignores the combined with other training factors. The abnormal development situation of physical fitness and sports performance is not proportional to the. The successful experience of the Liu Xiang 110 meter hurdles is showing physical fitness and technique which combines the benefits of training.

\section{SOME MEASURES AND SUGGESTIONS IN IMPROVING THE PHYSICAL FITNESS TRAINING LEVEL OF OUR COUNTRY'S TRACK AND FIELD PROJECT}

\section{A. To deepen understanding of the special physical ability training}

Physical fitness is the basis of the training track project, is the athlete's "hardware" factor, in order to achieve the excellent sport achievement, we are sure to add roughly training emphasis on strength, improve the science, effectiveness and flexibility of physical training. For the specific content of physical training, we should understand from practice, practice without theory is blind practice, no practice theory is the empty theory, and we should truly realize a combination of theory and practice.

\section{B. Developing scientific arrangement of physical training load, preventing excessive training}

Track and all other sports all need to obtain excellent results through long-term training days and months multiplying ability, namely the training process should be continuous, if damage appears in athlete's training or competition, it means that may interrupt training or competition, light injury need adjust for days or months, 
or even longer unable to return to the court. A majority of sports injury is caused by excessive training, so in training and competition, we must strengthen the prevention of over training consciousness, attention should be paid to the injured or small accident training may be a danger signal of over-training. To strengthen the monitoring in over-training, arrange the training load by the player itself and adapting to the conditions, emphasizing personalized.

\section{Pay attention to the physical recovery training after over training}

In order to prevent over training, attention should be paid to the recovery after training. The success in Ma Junren training are inseparable with his unique opinion about training and recovery, he thought that the training is a process of "recovery training recovery training", the recovery should be put in the first place, although many people think it is the "wild west", but success in "Majiajun" can not be denied one day, a day of training, a marathon training does exist, the Japanese middle distance race team had reached day 1.5 marathon. In addition, Ma Junren on the athlete's nutrition and physical recovery also take a variety of methods, both traditional Chinese medicine Guben, conditioning also has western medicine, and have achieved certain results.

\section{CORRESPONDING AUTHOR}

Bin Xu. College of Foreign Languages, Northeast Dian li University, Jilin, 132012, China. Email:34063479@qq.com.

\section{REFERENCES}

[1] Zhang Yingbo, the Track and Field of Physical Training [M]. Beijing: People's sports press, 2005, 1

[2] Tian. Sports Training Science [M]. Beijing: People's sports press, 2000, 2

[3] Chen Xiaoping Analysis on the "special ability" training - the main problems in Chinese training project [J]. China sports science and technology, 2002, 1 (38): 10-12.

[4] Qin Weifeng. Physical Training of Adolescent Athletes . [J].Track and Field, 2004, 9:47-48.

[5] Lin Jinqing, Ni Chaoguo. Track and field theory at home and abroad the latest development trend of $[\mathrm{J}]$. Chinese school physical education, 2001, 6:39-40. 